\title{
Polypropylene mesh-reinforced pancreaticojejunostomy for periampullar neoplasm
}

\author{
Di-Yu Huang, Xian-Fa Wang, Wei Zhou, Ying Xin, Yi-Ping Mou, Xiu-Jun Cai
}

Di-Yu Huang, Xian-Fa Wang, Wei Zhou, Ying Xin, Yi-Ping Mou, Xiu-Jun Cai, Depatment of Surgery, Sir Run Run Shaw Hospital, School of Medicine of Zhejiang University, Institute of Microinvasive Surgery of Zhejiang University, Hangzhou 310016, Zhejiang Province, China

Correspondence to: Dr. Xian-Fa Wang, Depatment of Surgery, Sir Run Run Shaw Hospital, Medical School of Zhejiang University, Institute of Microinvasive Surgery of Zhejiang University, 3 East Qingchun Road, Hangzhou 310016, Zhejiang Province, China. hdysrrsh@hotmail.com

Telephone: +86-13957119659 Fax: +86-571-86044817

Received: July 11, $2007 \quad$ Revised: August 31, 2007

\begin{abstract}
AIM: To evaluate the effect of polypropylene meshreinforced pancreatojejunostomy on pancreatic leakage.

METHODS: Seventeen consecutive patients with paraampullar malignancy received polyprolene meshreinforced pancreatodudeonectomy and the Child's method was used to rebuild the alimentary tract.
\end{abstract}

RESULTS: The mean time of polyprolene mesh-reinforced pancreatojejunostomy was $22 \mathrm{~min}$. Anastomosis could endure $30-500 \mathrm{~cm} \mathrm{H} \mathrm{H}_{2} \mathrm{O}$ pressure during operation. All patients recovered without pancreatic leakage.

CONCLUSION: Polyprolene mesh-reinforced pancreatojejunostomy is a feasible and reliable procedure to prevent pancreatic leakage.

\section{(C) 2007 WJG. All rights reserved.}

Key words: Pancreatic leakage; Pancreatojejunostomy; Anastomosis; Pancreatodudenectomy

Huang DY, Wang XF, Zhou W, Xin Y, Mou YP, Cai XJ. Polypropylene mesh-reinforced pancreaticojejunostomy for periampullar neoplasm. World J Gastroenterol 2007; 13(45): 6072-6075

http://www.wjgnet.com/1007-9327/13/6072.asp

\section{INTRODUCTION}

Pancreatic anastomotic leakage is a common lethal complication of pancreaticojejunostomy. The incidence of pancreatic anastomosis leakage depends on multiple factors, among which the anastomotic method is the key factor. Different anastomotic methods in pancreaticojejunostomy have been reported in the literature, but none of them is able to prevent pancreatic leakage. Recently, we designed a new anastomotic method: polypropylene mesh-reinforced pancreaticojejunostomy (MRP), by which the sheath of jejunum is bound to the pancreatic remnant wrapped by a strip of mesh. We have applied this method in 17 consecutive periampullar neoplasm patients, and none of them developed pancreatic leakage.

\section{MATERIALS AND METHODS}

\section{Clinical data}

Nine male and eight female patients with periampullar malignancy, aged 38-72 years, were included in this study, including 6 patients with carcinoma of the panceatic head, 6 with distal common bile duct cancer, 3 with ampullar carcinoma and 2 with duodenal carcinoma. All the patients received polypropylene mesh-reinforced pancreatoduodenectomy and the Child's method was used to rebuild the alimentary tract. Initial polypropylene MRP was performed on 16 patients, the other patient received end-to-end inviganation anastomosis during the first operation but developed pancreatic leakage after operation. On the $8^{\text {th }}$ postoperative day, the patient developed massive intraabdominal bleeding and received the second laparotomy along with polypropylene MRP.

\section{Technique}

The pancreas was transected with a scalpel on the scheduled line. Hemostasis was secured by suture ligatures with 4-0 polyprolene stitches (Ethicon, Somerville, NJ) or electrocautery. A $3.0 \mathrm{~cm}$ cut end of the pancreatic remnant was isolated. A $1.0 \mathrm{~cm}$ wide polypropylene mesh (Ethicon, Somerville, NJ) strip was tightly wrapped over the pancreatic stump about $1.0 \mathrm{~cm}$ from the cut margin with a few stitches. The mesh was fixed if it could not be moved with force. If the main pancreatic duct was identified, a stent tube was inserted into the main pancreatic duct and fixed with suturing thread (Figure 1A). Then, the pancreatic stump and the free margin of jejunum were brought together. A posterior row of continuous running sutures using a 3-0 polyprolene stitch was placed between the inner edge of the mesh and jejunum. The sutures were passed carefully through the 

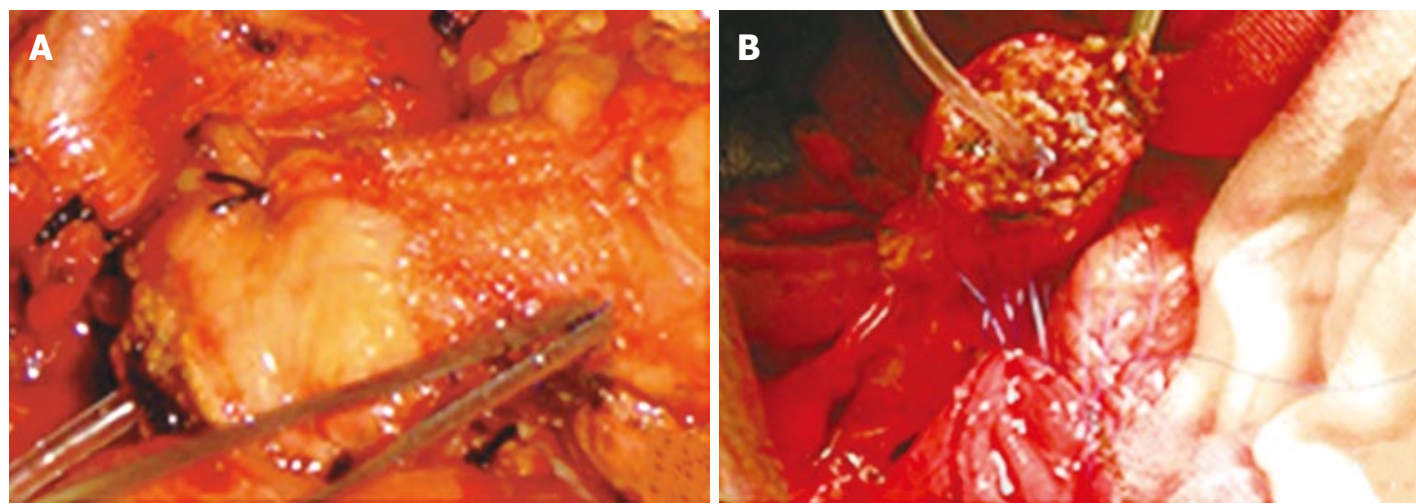

Figure 1 Fixation of mesh around the pancreatic stump (A); running suture on the posterior wall of pancreas with a stitch placed between inner edges of the mesh and jejunum (B); invagination of the pancreatic stump into the jejunum (C); running suture on the anterior wall of the pancreas with a stitch placed between inner edges of the mesh
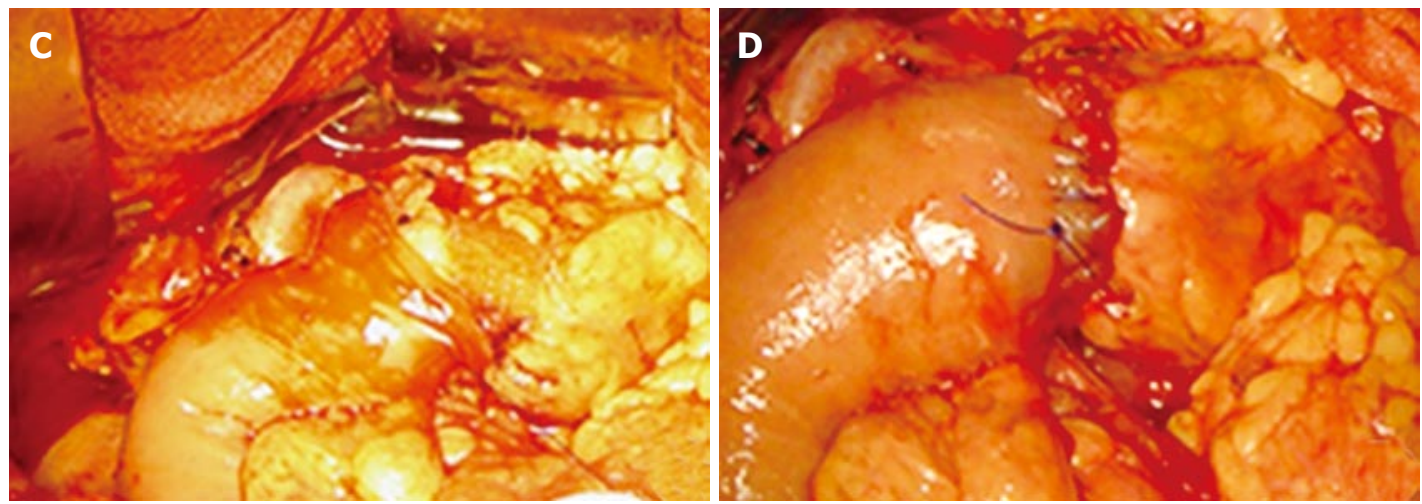
and jejunum (D).

mesh, pancreatic capsule and full thickness of jejunum. We began at the farthest point on the cranial side of the pancreatic stump and the caudal side was ligated with six to eight sutures (Figure 1B). After the posterior sutures were completed, they were gently pulled to invaginate the pancreatic stump into the jejunum (Figure 1C). The opposite end of the pancreatic duct stent tube was traversed through sites where bilioenteric anastomosis was performed. Finally, the continuous sutures were extended anteriorly using the same stitch. The sutures were tied after the tightness of the suture line was confirmed. As a result, the jejunal stump invaginated the pancreatic stump of about $2.0 \mathrm{~cm}$ (Figure 1D). Care was taken to cover the entire mesh in the jejunal lumen. A urinary catheter was inserted into the jejunum, and saline solution was injected to test for a watertight closure. The seromuscular surface of jejunum $1.0 \mathrm{~cm}$ from the margin was anchored to the superior and inferior peritoneal attachments of the pancreatic body to minimize the tension. Biliary anastomosis was constructed in an end-to-side fashion $15 \mathrm{~cm}$ distal from the pancreaticojejunostomy. Then a Jackson-Pratt drainage tube was placed near the anastomosis. Daily output and amylase content of abdominal drainage were measured after operation. Pancreatic leakage was defined as the persistent amylase-rich (more than three times the serum concentration) drainage output excess $50 \mathrm{~mL} /$ $\mathrm{d}^{[1,2]}$. Prophylactic octreotide was not used.

\section{RESULTS}

The mean operative time for polypropylene MRP was $22 \mathrm{~min}$ (ranged 10-25 min). No pancreatic leakage was observed under the pressure of $20 \mathrm{~cm} \mathrm{H}_{2} \mathrm{O}$ during operation. The abdominal drainage output was less than
$50 \mathrm{~mL}$ in 14 patients, and the amylase content in drainage was within normal range (ranged 46-98 IU/L). The abdominal drainage was removed 4-5 d after the operation, and the patients recovered well and were discharged on the $10^{\text {th }}$ postoperative day. Two patients had a high volume of abdominal drainage during the first 3 postoperative days, but the amylase content in the abdominal drainage was within normal range. The abdominal drainage was removed on the $7^{\text {th }}$ postoperative day and the patients recovered well. A 55-year old male patient received pancreaticojejunectomy for distal common bile duct with an end-to-end invagination anastomosis. The pancreas was soft and fragile. The abdominal drainage output was $>$ $100 \mathrm{~mL} / \mathrm{d}$ after operation and the amylase content was $>$ 2000 IU/L. Pancreatic anastomotic leakage was identified. The patient had no fever or abdominal pain and received conservative therapy initially. On the $8^{\text {th }}$ postoperative day, fresh blood was drained from the abdominal drainage tube and the patient received the second laparotomy. During the operation, laceration of pancreatic tissue was found on the suture of anastomosis with massive fluid collection. The bleeding came from the splenic artery involved in the fluid collection. After the bleeding was stopped, the pancreas was found to be edematic and fragile. In order to make a direct suture on the pancreas, we decided to perform polypropylene MRP. The patient recovered well after the second operation without pancreatic leakage. All patients were followed up in the outpatient clinic and no adverse events occurred.

\section{DISCUSSION}

Since Whipple introduced pancreaticoduodenectomy, it has become a standard procedure for malignant and 
benign disorders of the pancreatic head and periampullary region ${ }^{[3-5]}$. Although the mortality from the surgical procedure has come down considerably during the past three decades $^{[6]}$, it is still higher than that of other radical procedures for abdominal malignancy ${ }^{[7-9]}$. Pancreatic anastomotic leakage is still the most important determinant of its morbidity, with an incidence of $2 \%-14 \%{ }^{[10,11]}$ and mortality of $28 \%{ }^{[12,13]}$. The etiology of pancreatic anastomotic leakage covers several aspects, including quality of pancreatic tissue, size of major pancreatic duct, exocrinal status of pancreas, general condition and nutritional status of the patient, skill of the surgeon and method of pancreaticojejunostomy ${ }^{[6,14-16]}$. Among them, method of pancreaticojejunostomy seems to be the key factor $^{[17]}$. Different methods for pancreaticojejunostomy have been reported in the literature ${ }^{[19]}$, including end-toside anastomosis, duct-to-mucosa anastomosis, or end-toend or end-to-side invagination anastomosis. The suturing techniques for anastomosis include running or interrupted suture, single layer or double layers suture ${ }^{[18-20]}$. But all these methods cannot absolutely prevent the leakage, the incidence of leakage of the most widely applied end-toside invagination anastomosis is still as high as $11 \%{ }^{[21]}$. No consensus on the choice of anastomotic technique has been reached, and currently each technique finds its application among different groups of surgeons ${ }^{[2]}$.

It is well known that the incidence of pancreatic leakage is higher in patients with a soft and normal pancreatic parenchyma because it is prone to develop parenchymal laceration from shear forces applied during tying of the sutures, especially while performing suturing on the posterior wall of the pancreas. In patients with normal pancreatic parenchyma, the incidence of leakage is $12 \%$ to $28 \%$, compared with $5 \%$ to $9 \%$ in those considered to have pancreatic fibrosis ${ }^{[23]}$. The efferent loop filled with bile and pancreatic juice also increases the shear force ${ }^{[24]}$. Some retrospective or prospective studies also suggested that technical modifications may reduce the leakage rate ${ }^{[25-27]}$, suggesting that if the pancreas is soft with a narrow duct, it would be most secure when the pancreaticojejunal anatomosis is intraluminal into the jejunum by invaginating the pancreatic stump.

Polyprolene mesh-reinforced pancreaticojejunostomy was developed based on the binding pancreaticojejunostomy described by Peng et al ${ }^{[28,29]}$, who reported a widely invaginated end-to-end anastomosis with ablated jejunal mucosa. Our procedure with single layer continuous sutures is less complicated than the binding pancreaticojejunostomy. The success of this technique may be due to the following four aspects. First, the mesh forms a safe "clothing" around the remnant pancreas for anchoring sutures, thus preventing the possibility of parenchymal laceration and bleeding from the sutures in soft pancreatic parenchyma caused by the suture. We identified the advantages of a new technique in the case where a secondary polypropylene MRP was received for leakage from the first operation site. During the second operation, the pancreatic parenchyma was severely edematic and fragile, making the direct suture impossible. However, it was easy and convenient to perform polypropylene MRP on this patient, and no leakage occurred postoperatively. Second, sine the shape of the pancreatic stump can be modified and reduced by the mesh, it is more convenient to make an invagination. Third, the posterior single layer continuous sutures are simple and require less time. Fourth, it is very convenient to perform polypropylene MRP under different conditions and the time required is less than single end-to-end invagination. The mesh in the anastomosis can promote fibroblast attachment and enhance the anastomotic healing process ${ }^{[30,31]}$. However, it still needs further confirmation.

An ideal pancreaticojejunal anastomosis should be safe and convenient. Moreover, laparoscopy is more and more widely applied by general surgeons, and the convenience of a surgical procedure should be considered. The use of polypropylene MRP ensures a tight seal for any type of pancreatic stump regardless of the pancreas consistency, thus a more secure and reliable anastomosis can be obtained. The preliminary results are very encouraging. However, an appropriate prospective study in randomized patients is needed. Up to date, we have not observed any adverse effect of polypropylene MRP, but a long following-up time is needed to confirm it.

\section{COMMENTS}

\section{Background}

Pancreaticoduodenectomy is the standard procedure for malignant and benign disorders of the pancreatic head and periampullary region. Mortality and morbidity of this procedure are still higher than other radical procedures for abdominal malignancy. Pancreatic anastomotic leakage is still the most important determinant of its morbidity.

\section{Research frontiers}

The method of pancreaticojejunostomy is the key factor for pancreatic anastomotic leakage. We designed a new technique of polypropylene mesh-reinforced pancreaticojejunostomy to prevent pancreatic leakage.

\section{Innovations and breakthroughs}

Up to date, all the existing methods of pancreaticojejunostomy cannot perish anastomotic leakage. Our new method is effective in preventing pancreatic leakage.

\section{Applications}

This technique is safe and can be applied in pancreaticoduodenectomy under all conditions even though the pancreas is very fragile. If its advantage and disadvantage can be proved by large clinical trials, it can be used as one of the standard procedures.

\section{Terminology}

Pancreaticoduodenectomy: excision of the pancreatic head and the encircling loop of the duodenum to which it is connected. Pancreaticojejunostomy: surgical anastomosis of the pancreatic duct or the divided end of transected pancreas with the jejunum

\section{Peer review}

This article seems to be a challenging artifice to reduce postoperative complication in pancreatic surgery. The results are encouraging and the procedure can be used as a standard method of pancreaticojejunostomy.

\section{REFERENCES}

1 Bassi C, Dervenis C, Butturini G, Fingerhut A, Yeo C, Izbicki J, Neoptolemos J, Sarr M, Traverso W, Buchler M. Postoperative pancreatic fistula: an international study group (ISGPF) definition. Surgery 2005; 138: 8-13 
2 Alexakis N, Sutton R, Neoptolemos JP. Surgical treatment of pancreatic fistula. Dig Surg 2004; 21: 262-274

3 Z'graggen $\mathbf{K}$, Uhl W, Friess H, Büchler MW. How to do a safe pancreatic anastomosis. J Hepatobiliary Pancreat Surg 2002; 9: 733-737

4 Liao Q, Zhu Y. [Surgical management of pancreatic cancer: current practice and future prospect]. Zhongguo Yixue Kexueyuan Xuebao 2005; 27: 556-559

5 Warshaw AL, Thayer SP. Pancreaticoduodenectomy. J Gastrointest Surg 2004; 8: 733-741

6 Poon RT, Lo SH, Fong D, Fan ST, Wong J. Prevention of pancreatic anastomotic leakage after pancreaticoduodenectomy. Am J Surg 2002; 183: $42-52$

7 Glasgow RE, Jackson HH, Neumayer L, Schifftner TL, Khuri SF, Henderson WG, Mulvihill SJ. Pancreatic resection in Veterans Affairs and selected university medical centers: results of the patient safety in surgery study. J Am Coll Surg 2007; 204: 1252-1260

8 Ohwada S, Ogawa T, Kawate S. Results of duct-to-mucosa pancreaticojejunostomy for pancreaticoduodenectomy Billroth I type reconstruction in 100 consecutive patients. J Am Coll Surg 2001; 193: 29-35

9 Topal B, Aerts R, Hendrickx T, Fieuws S, Penninckx F. Determinants of complications in pancreaticoduodenectomy. Eur J Surg Oncol 2007; 33: 488-492

10 Andre T, Hammel P, Lacaine F, Palazzo L, Becouarn Y, Mornex F. Cancer of the pancreas. Gastroenterol Clin Biol 2006; 30 Spec No 2: 2S75-2S80

11 Lin JW, Cameron JL, Yeo CJ, Riall TS, Lillemoe KD. Risk factors and outcomes in postpancreaticoduodenectomy pancreaticocutaneous fistula. J Gastrointest Surg 2004; 8: 951-959

12 van Berge Henegouwen MI, De Wit LT, Van Gulik TM, Obertop H, Gouma DJ. Incidence, risk factors, and treatment of pancreatic leakage after pancreaticoduodenectomy: drainage versus resection of the pancreatic remnant. J Am Coll Surg 1997; 185: 18-24

13 Fahy BN, Frey CF, Ho HS, Beckett L, Bold RJ. Morbidity, mortality, and technical factors of distal pancreatectomy. Am J Surg 2002; 183: 237-241

14 Poon RT, Lo SH, Fong D, Fan ST, Wong J. Prevention of pancreatic anastomotic leakage after pancreaticoduodenectomy. Am J Surg 2002; 183: 42-52

15 Brozzetti S, Mazzoni G, Miccini M, Puma F, De Angelis M, Cassini D, Bettelli E, Tocchi A, Cavallaro A. Surgical treatment of pancreatic head carcinoma in elderly patients. Arch Surg 2006; 141: 137-142

16 Abete M, Ronchetti V, Casano A, Pescio G. Pancreatic fistula after pancreaticoduodenectomy: risk factors and treatment. Minerva Chir 2005; 60: 99-110

17 Yang YM, Tian XD, Zhuang Y, Wang WM, Wan YL, Huang YT. Risk factors of pancreatic leakage after pancreaticoduodenectomy. World J Gastroenterol 2005; 11: 2456-2461

18 Popiela T, Kedra B, Sierzega M, Gurda A. Risk factors of pancreatic fistula following pancreaticoduodenectomy for periampullary cancer. Hepatogastroenterology 2004; 51 1484-1488

19 Sikora SS, Posner MC. Management of the pancreatic stump following pancreaticoduodenectomy. Br J Surg 1995; 82: 1590-1597

20 Hines OJ, Reber HA. Technique of pancreaticojejunostomy reconstruction after pancreaticoduodenectomy. J Hepatobiliary Pancreat Surg 2006; 13: 185-189

21 Peng SY, Wang JW, Lau WY, Cai XJ, Mou YP, Liu YB, Li JT. Conventional versus binding pancreaticojejunostomy after pancreaticoduodenectomy: a prospective randomized trial. Ann Surg 2007; 245: 692-698

22 Stojadinovic A, Brooks A, Hoos A, Jaques DP, Conlon KC, Brennan MF. An evidence-based approach to the surgical management of resectable pancreatic adenocarcinoma. J Am Coll Surg 2003; 196: 954-964

23 Shrikhande SV, Qureshi SS, Rajneesh N, Shukla PJ. Pancreatic anastomoses after pancreaticoduodenectomy: do we need further studies? World J Surg 2005; 29: 1642-1649

24 Bartoli FG, Arnone GB, Ravera G, Bachi V. Pancreatic fistula and relative mortality in malignant disease after pancreaticoduodenectomy. Review and statistical meta-analysis regarding 15 years of literature. Anticancer Res 1991; 11: 1831-1848

25 Jacob DA, Bahra M, Langrehr JM. Jejunal loop drainage versus direct pancreatic duct drainage after pancreatic head resection. Surg Today 2006; 36: 898-907

26 Ibrahim S, Tay KH, Launois B, Ta NC. Triple-layer ductto-mucosa pancreaticojejunostomy after pancreaticoduodenectomy. Dig Surg 2006; 23: 296-302

27 Imaizumi T, Hatori T, Tobita K, Fukuda A, Takasaki K, Makuuchi H. Pancreaticojejunostomy using duct-to-mucosa anastomosis without a stenting tube. J Hepatobiliary Pancreat Surg 2006; 13: 194-201

28 Batignani G, Fratini G, Zuckermann M, Bianchini E, Tonelli F. Comparison of Wirsung-jejunal duct-to-mucosa and dunking technique for pancreatojejunostomy after pancreatoduodenectomy. Hepatobiliary Pancreat Dis Int 2005; 4: 450-455

29 Peng SY, Mou YP, Liu YB. Binding pancreaticojejunostomy: 150 consecutive cases without leakage. J Gastrointest Surg 2003; 7: 898-900

30 Mu DQ, Dong QH, Peng SY, Peng CH, Wu YL. Surgical management of transected injury to the pancreatic neck. Chin J Traumatol 2003; 6: 205-208

31 Continenza MA, Vicentini C, Paradiso-Galatioto G, Fileni A, Tchokogoue E. In vitro study of Human Dermal Fibroblasts seeded on two kinds of surgical meshes: monofilamented Polypropylene and multifilamented Polyestere. Ital J Anat Embryol 2003; 108: 231-239

32 Di Vita G, Patti R, D’ Agostino P, Ferlazzo V, Angileri M, Sieli G, Buscemi S, Caruso G, Arcara M, Cillari E. Modifications in the production of cytokines and growth factors in drainage fluids following mesh implantation after incisional hernia repair. Am J Surg 2006; 191: 785-790

S- Editor Liu Y L- Editor Wang XL E- Editor Ma WH 